\title{
Applying Adaptive Neural Fuzzy Inference System to Improve Concrete Strength Estimation in Ultrasonic Pulse Velocity Tests
}

\author{
Loan T. Q. Ngo iD, Yu-Ren Wang $(\mathbb{D}$, and Yi-Ming Chen \\ Department of Civil Engineering, National Kaohsiung University of Science and Technology, Kaohsiung, Taiwan \\ Correspondence should be addressed to Yu-Ren Wang; yrwang@kuas.edu.tw
}

Received 20 March 2018; Revised 23 July 2018; Accepted 7 August 2018; Published 20 September 2018

Academic Editor: Arnaud Perrot

Copyright (c) 2018 Loan T. Q. Ngo et al. This is an open access article distributed under the Creative Commons Attribution License, which permits unrestricted use, distribution, and reproduction in any medium, provided the original work is properly cited.

\begin{abstract}
When inspecting the property of material, nondestructive testing methods are more preferable than destructive testing since they do not damage the test sample. Nondestructive testing methods, however, might not yield the same accurate results in examining the property of material when compared with destructive testing. To improve the result of nondestructive testing methods, this research applies artificial neural networks and adaptive neural fuzzy inference system in predicting the concrete strength estimation using nondestructive testing method, the ultrasonic pulse velocity test. In this research, data from a total of 312 cylinder concrete samples were collected. Ultrasonic pulse velocity test was applied to those 312 samples in the lab, following the ASTM procedure. Then, the testing results of 312 samples were used to develop and validate two artificial intelligence prediction models. The research results show that artificial intelligence prediction models are more accurate than statistical regression models in terms of the mean absolute percentage error.
\end{abstract}

\section{Introduction}

Examining concrete compressive strength in existing structure is one of the most important issues in the construction industry. The compressive strength serves as one of the most essential factors in quality assurance for concrete. There are nondestructive and destructive methods to test the compressive strength of concrete. Nondestructive testing (NDT) methods will not only not damage the concrete structure but they are also economic and feasible. A common NDT method to inspect the compressive strength of the concrete is ultrasonic pulse velocity (UPV) testing. UPV testing is mainly used to measure the pulse velocity of the concrete, and then the compressive strength of the concrete is interpolated. UPV testing can effectively evaluate the uniformity and relative quality of concrete structures. Moreover, UPV testing has a lot of advantages like low cost, easy to operate, and convenient to carry. The disadvantage of the NDT methods in general is that they are qualitative and have an average of $20 \%$ mean absolute percentage error (MAPE) when compared with destructive methods [1]. To enhance the accuracy in estimating compressive strength, a combination of destructive and nondestructive methods has been proposed in $[2,3]$. A combination of UPV testing and rebound hammer test was employed in $[2,3]$.

With the development of artificial ntelligence (AI) technology, incorporating AI in enhancing the accuracy of compressive strength has become a new research approach. Cho and Pham [4] employ AI technology including support vector machines, artificial neural networks (ANNs), chisquared automatic interaction detector, and linear regression to predict the compressive strength of high performance concrete. Adaptive neural fuzzy inference systems (ANFIS) is also an effective (AI) prediction method. Vakhshouri and Nejadi [5] have concluded that the ANFIS model gave the best prediction of the compressive strength of selfcompact concrete. Comparing ANNs, ANFIS, and multiple linear regression in estimating the compressive strength of concrete, $[6,7]$ state that ANNs and ANFIS are suitable prediction models. Based on the reliability of ANNs and ANFIS, this research has chosen those two AI technologies in enhancing the prediction of concrete compressive strength in UPV testing. 
In concrete, the actual compressive strength is the unconfined one or the self-compacted one [8]. One of the NDT methods commonly used to measure the actual compressive strength is UPV test. UPV test is done based on the principle of measuring the travelling time of an ultrasonic pulse in concrete sample. Then, the ultrasonic pulse velocity is obtained. Based on the velocity information, the actual compressive strength of concrete sample is evaluated. It is shown in previous researches that the higher the ultrasonic pulse velocity, the better the quality of concrete sample $[9,10]$.

The compressive strength of concrete is predicted using a constructed prediction model. Since there are many ways to construct this prediction model, Kademi [11] stated that using multiple linear regression to develop the model cannot give an accurate prediction of compressive strength. Artificial neural network, on the other hand, is more suitable for estimating the property of concrete sample $[12,13]$.

This research aims to improve the prediction of concrete compressive strength in UPV test with the help of ANNs and ANFIS. A linear and a nonlinear regression prediction models were developed. Then, 312 test samples that underwent UPV testing from a local laboratory were collected. 252 out of the 312 test samples were randomly chosen to be the training dataset. The remaining 60 test samples were used to evaluate the accuracy of the prediction model developed.

The rest of this paper is organized as follows: Section 2 is the literature review, the methodology of the research is described in Section 3, the prediction results are discussed in Section 4, and the conclusion is discussed in Section 5.

\section{Literature Review}

Since destructive testing is not preferable in some applications, nondestructive testing methods have attracted lots of interests in the field of concrete structure assessment. NDT does not require much on sample preparation and its testing equipment is quite simple [14]. Therefore, NDT can be applied easily and economically to assess concrete structure properties. In addition, due to the limitation of laboratory equipment, NDT methods are preferable for the prediction process [15]. Based on the relationship between strength and NDT parameters, the strength of concrete will be evaluated. The detail information of the empirical relationship between strength and NDT parameters is provided by the NDT equipment manufacturers. The information provided is directly related to the testing system used in NDT methods, and it is not always suitable for all type of concrete. Hence, the calibration of different types of concrete is necessary $[16,17]$. UPV testing method is one of the most popular NDT methods that is successfully used to evaluate the property of concrete.

Ultrasonic pulse velocity (UPV) test uses the propagation of sound wave through material to measure the depth of material. It also gives information on damages inside the material. From the data measured by UPV test, the material strength and low-strain elastic modulus can be calculated or predicted [18-20]. It has been shown in [21] that UPV of concrete is inversely proportional to the volume of pores inside and develops with age of the concrete. The UPV rate of change can be used to determine the setting of concrete and give inside information on the changes at the microstructural level of concrete in early ages [22, 23]. The research in [24] found the effect of microstructural variations on UPV in mortar. This is used to estimate the sand content in mortar. UPV testing is also used to detect damages inside concrete effectively in $[25,26]$. UPV testing has been shown to be the effective testing method for different types of concrete such as lightweight or asphalt concrete in [27-29]. UPV testing measures the ultrasonic wave speed when it penetrates through materials in order to predict the strength of the materials, find any changes in condition of the materials, internal flaws, and other factors. UPV technique, however, is not always practical for all types of concrete samples. Since there is sound wave related to the method, it is not accurate for samples that have internal water-filled cracks and rough surfaces [30]. To increase the accuracy of the testing, for rough surfaces, a coupling gel is applied in between the transducer of testing equipment and roughness samples to smoothen the contact layer. Many studies have been conducted in detail to investigate the correlation between UPV and concrete strength; however, not many literature results on the correlation between parameters of UPV and properties of concrete have been found $[17,19,20,27]$. In addition, there are many factors that affect the one important parameter of UPV, the ultrasonic pulse velocity. This leads to the derivation on the relationship between UPV parameters and concrete properties unreliable [17]. Therefore, the risk level in the evaluating process must be defined quantitatively. Recently, artificial intelligent technology has been employed into predicting the compressive strength of concrete. In addition to using UPV test, the adaptive neuro fuzzy inference system (ANFIS) and the artificial neural network (ANN) are used to give more precise prediction on the compressive strength under various conditions of the mix proportion of concrete [24, 31]. It states in $[32,33,34]$ that inverse modelling of concrete compressive strength has been developed with statistical techniques or artificial intelligent techniques. Among AI techniques, ANNs is quite popular and user friendly for the process after the prediction model is established. One advantage of ANNs is that there is no requirement in defining the explicit input-output relationship as in the conventional regression. In ANNs, the neuron used is the information processing system unit. This system unit consists of connection links and summation/activation functions. Each neuron receives input and weights from neurons belonging to the previous layer of this neuron in the training process [34]. The learning process in ANNs is adaptive. Applying ANNs does not require any prior knowledge of the functional relationship among the variables. The distributed processing system of ANNs is a parallel one that consists of one input and one output layer, and one or more hidden layers connecting by neurons. There are different types of ANNs developed like the multilayer feed-forward neural network or the cascade-forward neural network [35]. Applying ANNs in predicting the compressive strength of 
concrete has been studied by researchers and several authors have applied ANNs in structural engineering [36, 37].

Combining ANNs with the fuzzy inference system, ANFIS is a hybrid neuro-fuzzy approach. ANFIS has the adaptive learning algorithm and the reasoning ability, which is a well-known approach to model complex nonlinear system [38]. Fuzzy inference system (FIS) is a linguistic rulebased system that can represent any system with high accuracy. FIS is regarded as the universal approximator [39]. The downside of FIS is lacking self-adaptability and selflearning ability when there is a change in the external environment. With that, ANFIS takes the learning property of neural network in combination with FIS to create an approach for forecasting and regression [40]. Author P.J.L. Adeodato (2011) predicted the concrete compressive strength by applying a sensor-based forecasting model using ANFIS. The results showed that ANFIS gives lower error in prediction when compared with conventional backpropagation neural networks [41].

Prediction models take measured data as input variables in their data-driven modelling. The models learn through the training step from a collection of training patterns. This paper uses ANN and ANFIS as two different prediction models with the aim of predicting more accurate concrete compressive strength in UPV tests.

\section{Experiment Methodology}

Two artificial intelligence models used to integrate data in this study are ANNs and ANFIS. Using AI approach is expected to improve the performance of predicting the concrete compressive strength when compared with the conventional approach. The model development is shown in Figure 1. According to Khademi [42], the generalization of the predictive models can be enhanced, but their effectiveness needs further examination.

In this study, data were collected from both destructive tests and nondestructive tests using 28-day cylinder concrete specimens. They are stored in standard curing conditions before conducting the tests. The UPV measurements are taken against all the cylinder concrete samples with a diameter of $12 \mathrm{~cm}$ and a height of $24 \mathrm{~cm}$. Before collecting the cylinder to the laboratory, the mixture must be cleaned and greased to adherence between the sample and mold after casting. After 2-3 days of casting, the specimens are slightly demanded and carefully be transferred to store in air environment in the laboratory room. The process is shown in Figure 2.

3.1. Destructive Concrete Compressive Strength Test. In this study, the actual compressive strength of concrete is investigated according to the Taiwan National CNS1232 standard. "Compressive strength of cylindrical concrete specimens" is the method that determines the compressive strength of cylindrical concrete samples such as monolithic concrete sample or core drilled cylindrical concrete sample. The testing device, HT-8391 hydraulic machine, is able to produce up to 200 tons of press force on the surface of the concrete sample. This procedure follows the study of [43].
First, measure the diameter and height of the cylindrical concrete sample. Then, eliminate all the strange objects on the surface of the test object and on the surface of the pressure machine as in Figure 3. The test object will be placed concentrically with the surface of the pressure machine. The compressive force will be increased from $1.50 \mathrm{kfg} / \mathrm{cm}^{2}$ $(0.150 \mathrm{MPa})$ to $3.50 \mathrm{kfg} / \mathrm{cm}^{2}(0.35 \mathrm{MPa})$ per second. For the first half of the test, the highest compressive force will be predicted to increase the force until the test sample is broken. Then, the maximum compressive force for that test sample will be recorded.

3.2. Ultrasonic Pulse Velocity. Ultrasonic pulse velocity (UPV) in concrete is an important parameter in evaluating concrete's properties [44]. UPV testing measures the ultrasonic wave speed when it penetrates through materials in order to predict the strength of the materials, find any changes in condition of the materials, and find any internal flaws, and the travelling distance has a full report on the correlation between the compressive strength [45]. UPV technique, however, is not always practical for all types of concrete samples. Since there is sound wave related to the method, it is not accurate for samples that have internal water-filled cracks and rough surfaces [46]. The unconfined compressive strength (UCS) is the maximum longitudinal axial compressive stress of the sample [47]. The relationship between pulse velocity and compressive strength is also identified. In [41], Yu, L.Y., and Yong. S (2008) propose an empirical equation on the relationship between the unconfined compressive strength and the pulse velocity as follows:

$$
\mathrm{UCS}=a \cdot e^{b V},
$$

where the properties of material will determine $a$ and $b$, and $V$ is the speed of ultrasonic pulse.

In this study, the UPV test used follows the ASTM C59716: the standard test method for pulse velocity through concrete. The instrument used for UPV test is a TICO concrete ultrasonic detector developed by Proceq Company in Zurich, Switzerland. As shown in Figure 4, the instrument can perform the calculation and evaluation on functions of concrete uniformity, column hole, crack depth, elastic modulus, and concrete strength. The ultrasonic pulse velocity test conducted in this study is described as follows: the measurement was taken four times for each of the cylindrical concrete sample with a diameter of $12 \mathrm{~cm}$ and height of $24 \mathrm{~cm}$ as shown in Figure 5. For typical $3000 \mathrm{psi}\left(210 \mathrm{kgf} / \mathrm{cm}^{2}\right)$ concrete, for each cubic meter, the material properties are as follows: $325 \mathrm{~kg}$ cementing material (including $227.5 \mathrm{~kg}$ cement, $65 \mathrm{~kg}$ slag, and $32.5 \mathrm{~kg}$ fly ash), $180 \mathrm{~kg}$ water, $940 \mathrm{~kg}$ sand, $900 \mathrm{~kg}$ aggregate, and $3.25 \mathrm{~kg}$ chemical admixture.

The ultrasonic pulse velocity test was conducted for each of 312 test samples. First, one transducer was placed against one end of the test sample. The other transducer was placed at the other end of the test sample. The distance between the two transducers was measured as L. After the excitation measurement, the first Vaseline was applied between the transducer and the concrete surface, and the pressure wave was received. 


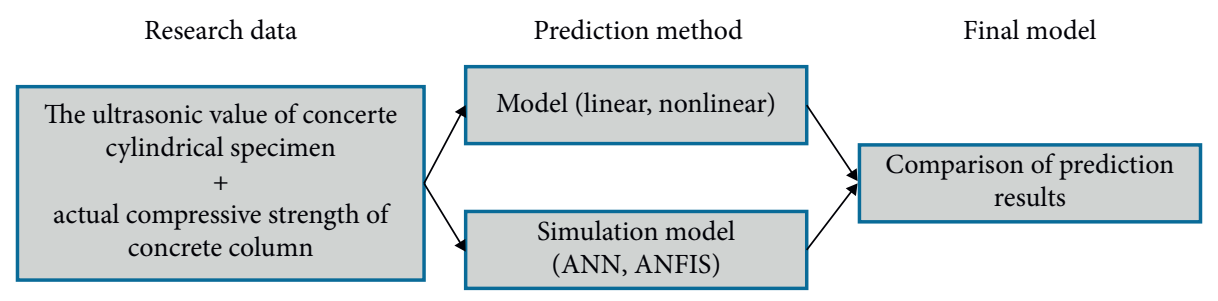

Figure 1: Model development.
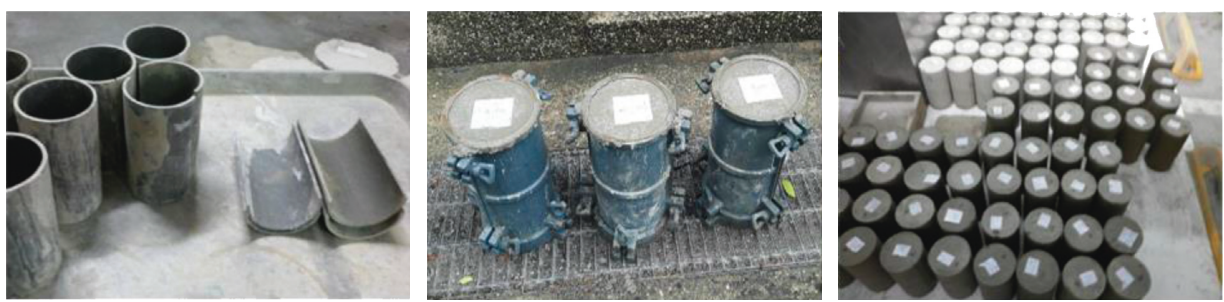

Figure 2: Cylinder collection process by the laboratory.

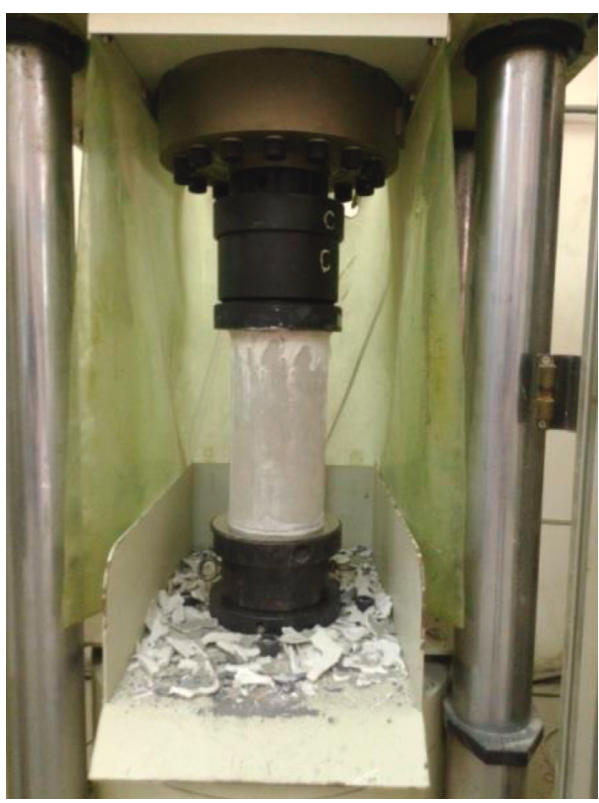

FIGURE 3: Concrete compressive strength test.

UPV test equipment consists of three parts: the ultrasonic pulser, the receive amplifier, and the time measurement device that indicates that the time of ultrasonic wave travel through the medium and the receiving transducer receives the signal. The measurement data are displayed and recorded in the control host.

To determine the velocity of ultrasonic pulse wave, two quantities are measured: the transmission distance and the duration ultrasonic pulses transmitted. The ultrasonic velocity $(v)$ was determined as follows:

$$
v=\frac{l}{t} 10^{3}
$$

where $l$ is the specimen length (peat-cement-sand brick with length measured in millimetres $(\mathrm{mm})), v$ is the velocity of ultrasound $(\mathrm{m} / \mathrm{s})$, and $t$ is the actual travelling time through medium of the ultrasonic pulse, measured in microseconds $(\mu \mathrm{s})$.

3.3. General Linear Regression. General linear regression (GLR) is used to estimate the correlation between input and output variables. The correlation that GLR estimates is between one response variable, which is a dependent variable, and two or more predictors, which are independent variables [48]. General linear regression has 2 categories:

(i) Linear regression: in the training data input, the margin is maximized by using the best hyperplane, that is, to define the hyperplane boundary as the training sample, and its range is the shortest distance between $\{+1,-1\}$ and the hyperplane.

(ii) Nonlinear regression: can use the nonlinear function to classify when the linear classification cannot be used. This type of data is transformed into a feature space by transforming it into a high-dimension feature space through a nonlinear mapping function $\Phi$.

The GLR form of a model uses a link function based on its distribution pattern which gives the relationship between $X$, as the predictor variable, and $y$, as the response variable [49].

The $(X-y)$ relational model is shown in the following equation:

$$
g(E(y))=X \times \beta+\mathrm{O}, \quad y \sim F,
$$

with selected link function $g(\cdot)$, offset variable $O$, the distribution model $F$ of $y$, predictor $X$, response variable $y$, and regression coefficient $\beta$.

3.4. Artificial Neural Networks. Artificial neural networks (ANNs) are simulations of the human brain with the ability of learning, adapting, and multivariate analyzing. With the advantages over traditional statistical methods, ANNs have 

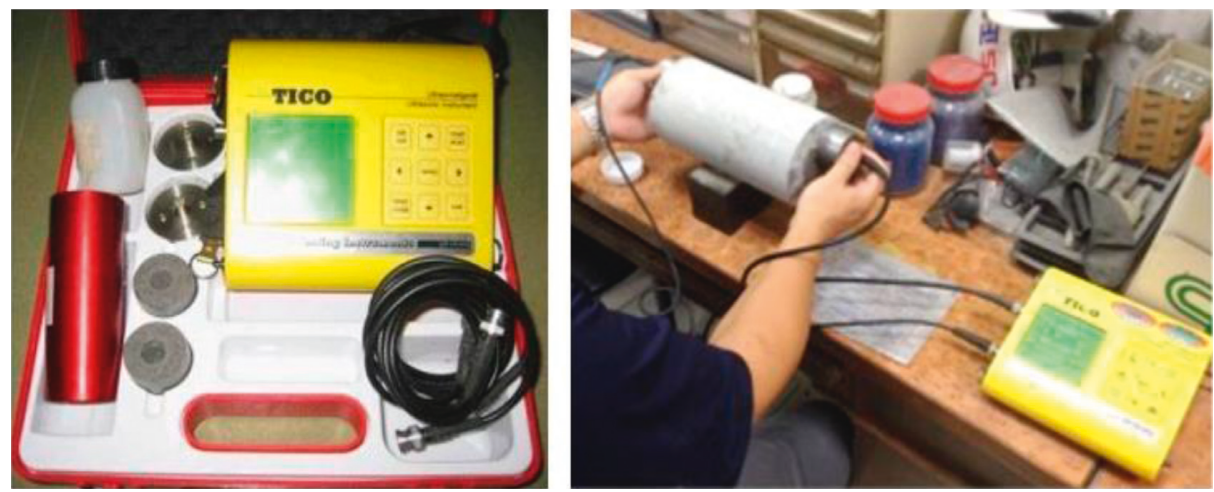

FIgURE 4: Ultrasonic pulse velocity test and TICO ultrasonic pulse velocity.

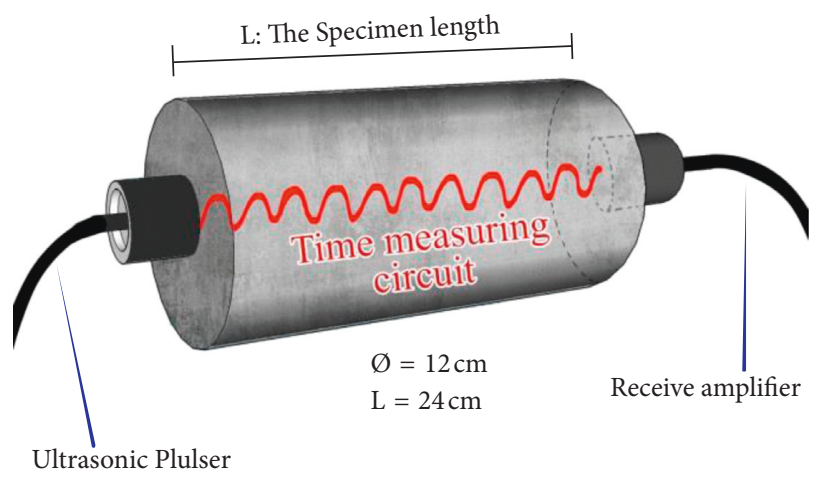

Figure 5: Model of schematic diagram of pulse velocity testing circuit.

the ability to do multiple regression analysis and give out complex interrelationships between dependent/independent variables through simple process elements $[49,50]$. The neuron used in ANNs is an information processing system unit that consists of connecting link, summation, and activation function [51]. As shown in Figure 6, for each neuron, it receives inputs and weights from neurons of the previous layer in the training process. Then, the weighted sum becomes an argument for the activation function in order to form the output [52]. Using mathematic modelling, a neuron output is calculated by using (4), (5), and (6) illustrated as follows:

$$
\begin{gathered}
u=\sum_{j=1}^{m} w_{j} x_{j}+b, \\
y=f(u), \\
f(u)=\frac{1+e^{-u}}{1-e^{-u}}
\end{gathered}
$$

where $x_{j}(j=1,2, \ldots, m)$ is the input signal from the previous layer, $w_{j}(j=1,2, \ldots, m)$ is the weight associated with $x_{j}, m$ is the number of inputs, $b$ is the bias, and $f(u)$ is the activation function.

To develop the ANN model, this paper used Neuro Solutions 7.0 software to construct a neural network model,

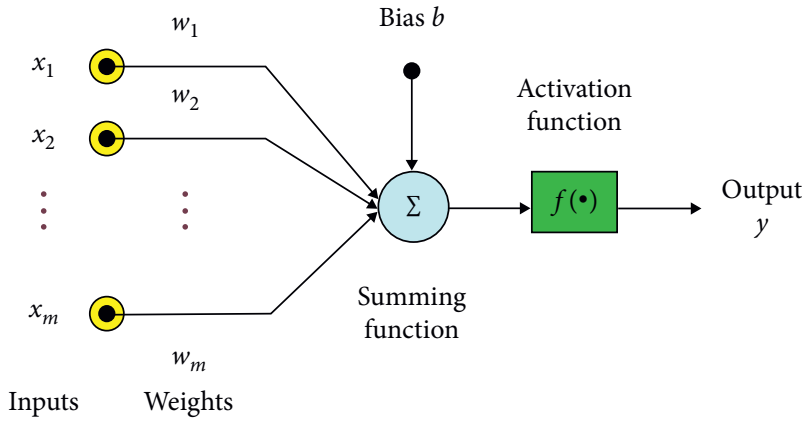

Figure 6: Model of network block [32].

speed of training, and host of neural network architectures. Backpropagation network (BPN) was also adopted for the prediction of concrete compressive strength. BPN supervised the training process. BPN used the gradient descent as the algorithm to find out the minimum mean of the error function in weight space.

With the testing data of 312 testing samples from the data testing laboratory, 252 industrial samples were randomly chosen as the training models set for the prediction. 20 samples were extracted from 252 training group data and they were set as the cross validation group. Then, the training process is used to find out the best prediction model. Finally, 60 remained data of 312 samples were used to evaluate the accuracy of the prediction model. As shown in Figure 7, the input layer in this study was the average ultrasonic pulse wave velocity. The output was the compressive strength of the concrete.

After setting the properties of the predictive model, the model was trained and tested to obtain the predictive value of the model. The result of the predictive model was judged by the mean absolute error percentage (MAPE), as shown in Figure 8.

The average velocity of the four ultrasonic waves obtained from each specimen was an independent variable. The compressive strength of the concrete was used to carry on the neural network analysis. Various modes have been tried to different training times. MAPE of the concrete strength and actual strength predicted by the model under different parameter settings is shown in Table 1 . 


\begin{tabular}{|c|c|c|}
\hline & 252 train & group data \\
\hline Number & $\begin{array}{c}\text { Average wave } \\
\text { speed }\end{array}$ & $\begin{array}{c}\text { Concrete strength } \\
\left(\mathrm{kgf} / \mathrm{cm}^{2}\right)\end{array}$ \\
\hline 1 & 3982.50 & 287 \\
\hline 2 & 3945.00 & 291 \\
\hline 3 & 4007.50 & 296 \\
\hline 4 & 4012.50 & 292 \\
\hline 5 & 3560.00 & 165 \\
\hline 6 & 3577.50 & 172 \\
\hline 7 & 3515.00 & 170 \\
\hline 8 & 3987.50 & 337 \\
\hline 9 & 4000.00 & 333 \\
\hline 10 & 3970.00 & 303 \\
\hline 11 & 3955.00 & 305 \\
\hline 12 & 3945.00 & 299 \\
\hline 13 & 3527.50 & 153 \\
\hline 14 & 3582.50 & 153 \\
\hline 15 & 4072.50 & 284 \\
\hline 16 & 4037.50 & 286 \\
\hline 17 & 3812.50 & 262 \\
\hline
\end{tabular}

\begin{tabular}{lcc} 
& & \\
& Input & testing group data \\
Number & $\begin{array}{c}\text { Average wave } \\
\text { speed }\end{array}$ & $\begin{array}{c}\text { Concrete strength } \\
\left(\mathrm{kgf} / \mathrm{cm}^{2}\right)\end{array}$ \\
\hline 252 & 4057.5 & 336 \\
253 & 4042.5 & 332 \\
254 & 4060 & 337 \\
255 & 3970 & 309 \\
256 & 4095 & 336 \\
257 & 4050 & 346 \\
258 & 4090 & 351 \\
259 & 3975 & 374 \\
260 & 4007.5 & 364 \\
261 & 3890 & 370 \\
262 & 3757.5 & 184 \\
263 & 4025 & 288 \\
264 & 4005 & 291 \\
265 & 4002.5 & 283 \\
256 & 4060 & 300 \\
267 & 3977.5 & 298 \\
268 & 3895 & 277 \\
\hline
\end{tabular}

Figure 7: ANNs model data collection process.

\begin{tabular}{lccc}
\hline $\begin{array}{l}\text { Average wave } \\
\text { speed }\end{array}$ & $\begin{array}{c}\text { Compressive } \\
\text { strength }\left(\mathrm{kgf} / \mathrm{cm}^{2}\right)\end{array}$ & $\begin{array}{c}\text { Predicted } \\
\text { strength }\left(\mathrm{kgf} / \mathrm{cm}^{2}\right)\end{array}$ & MAPE (\%) \\
\hline 4005 & 325 & 323.4327743 & 0.48 \\
4057.5 & 336 & 349.7252102 & 4.08 \\
4042.5 & 332 & 341.7911436 & 2.95 \\
4060 & 337 & 351.048794 & 4.17 \\
3970 & 309 & 311.4835861 & 0.80 \\
4095 & 336 & 368.9149015 & 9.80 \\
4050 & 346 & 345.7499542 & 0.07 \\
4090 & 351 & 366.4795062 & 4.41 \\
3975 & 374 & 312.7353884 & 16.38 \\
4007.5 & 364 & 324.5278274 & 10.84 \\
3890 & 370 & 309.7138242 & 16.29 \\
3757.5 & 184 & 205.8672991 & 11.88 \\
4025 & 288 & 332.8012024 & 15.56 \\
4005 & 291 & 323.4327743 & 11.15 \\
4002.5 & 283 & 322.3638208 & 13.91 \\
4060 & 300 & 351.048794 & 17.02 \\
\hline
\end{tabular}

FIgURE 8: Predictor of absolute error percentage in inverted transmitter ANNs.

3.5. Adaptive Neural Fuzzy Inference System. Adaptive neuro fuzzy inference system (ANFIS) is an adaptive network used to find responses for complex problems. In ANFIS, supervised learning is adopted. ANFIS is comprised of a learning algorithm, multilayer and feed-forward networks that include input/output variables, and a fuzzy rule.

The ANFIS multilayer contains 5 layers that work differently from each other; nodes in the same layer work similar to each other [53]. Figure 9 shows the framework structure of ANFIS with two input variables.

The fuzzy rule is illustrated as follows:

(i) Rule 1: if $x$ is $A_{1}, y$ is $B_{1}$, then $j=f_{1}=p_{1} x+q_{1} y+r_{1}$

(ii) Rule 2: if $x$ is $A_{2}, y$ is $B_{2}$, then $j=f_{2}=p_{2} x+q_{2} y+r_{2}$

where $A_{1}, A_{2} ; B_{1}, B_{2}$; and $C_{1}, C_{2}$ are the membership functions of each input $x$ and $y$ as part of the premises; $p_{1}, q_{1}$, $r_{1}$ and $p_{2}, q_{2}, r_{2}$ are linear parameters in the consequent part of Takagi-Sugeno fuzzy inference model [53].

In this study, the ANFIS modelling was performed in MATLAB to train and test data. 252 experimental data were used as the training group data (train data) of the neuronbased fuzzy inference system. The best predictive model was found by the model training process. 60 remained data were used as the test data into the best prediction model to calculate the average absolute error percentage. The concrete strength predicted by the model was compared with the compressive strength obtained from the destructive test. Then, the verification of the established model with the actual strength of concrete cylindrical test was made. The development of the ANFIS model in MATLAB follows the below steps:

Step 1. Import the training group and test group data using import instruction syntax as follows:

$$
\begin{aligned}
& \text { Traindata }=\text { xlsread (“traindata.xlsx") } \\
& \text { Testdata }=\text { xlsread (“testdata.xlsx") }
\end{aligned}
$$

Step 2. Create the ANFIS prediction model. This study attempts 32 different setups for the ANFIS prediction model: four membership functions with eight different types. This study uses the membership functions available in MATLAB like triangle, trapezoid, bell, gauss, bilateral Gaussian, double 
TABLE 1: Network model parameter setting.

\begin{tabular}{|c|c|c|}
\hline Network parameters of the project & \multicolumn{2}{|c|}{ Explanation } \\
\hline Internet usage examples model & \multicolumn{2}{|c|}{ Backpropagation neural network } \\
\hline & Training group & 232 set of data \\
\hline Sample selection (exemplars) & $\begin{array}{c}\text { Cross validation group } \\
\text { Test group }\end{array}$ & $\begin{array}{l}20 \text { set of data } \\
60 \text { set of data }\end{array}$ \\
\hline The number (hidden layers) & \multicolumn{2}{|c|}{ Layer 1 and layer 2} \\
\hline Transfer & \multicolumn{2}{|c|}{ Tanh Axon } \\
\hline Learning rule & \multicolumn{2}{|c|}{ Levenberg Marqua } \\
\hline Maximum epochs & \multirow{2}{*}{\multicolumn{2}{|c|}{$\begin{array}{l}\text { The default value is } 200 \text {, increased by the amount } \\
\text { (1) The minimum tolerable range (MSE) } \\
\text { (2) The maximum training period (epochs) }\end{array}$}} \\
\hline Termination & & \\
\hline Cumulative weights update method & \multicolumn{2}{|c|}{ Batch } \\
\hline
\end{tabular}

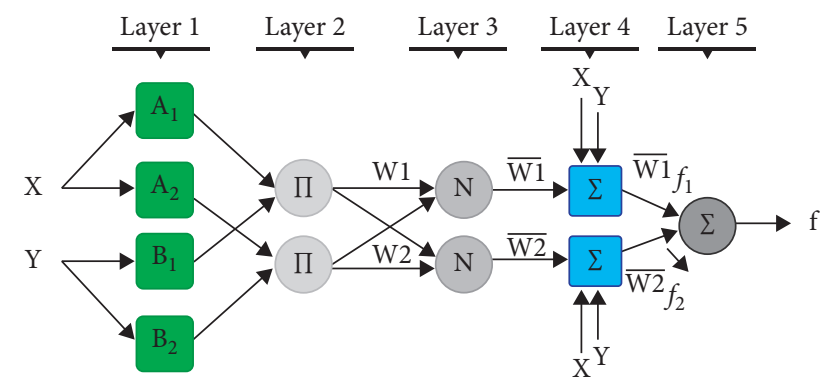

FIGURE 9: Structure of ANFIS model used in this study.

S-shaped, double S-shaped, and so on during the establishment of the prediction model.

Step 3. The model is set to be trained by the hybrid train FIS method with zero error tolerance and an epoch of 5000 .

Step 4. When the training model is completed, prediction value is exported using command syntax as follows:

$$
\text { Out_value }=\text { evalfis }(\text { testdata, fis } 1)
$$

A total of 32 ANFIS prediction models are established. With the prediction results obtained and the actual compression strength, the absolute percentage of error of the model and the prediction accuracy of the model can be calculated.

\section{Prediction Results}

Among the 312 test samples collected in the lab, 252 of them are randomly selected as the training dataset and 60 selected as testing dataset. The prediction accuracy is measured by the mean absolute percentage error (MAPE) illustrated in the following equation:

$$
M A P E=\frac{1}{n} \sum_{i=1}^{n}\left|\frac{A_{i}-P_{i}}{A_{i}}\right|,
$$

where $A_{i}$ is the actual concrete sample compressive strength and $P_{i}$ is the predicted strength.

In this research, there are two different AI-based prediction models: (a) the artificial neural network (ANN) and (b) the adaptive neural fuzzy inference system (ANFIS). For these models, the actual compressive strength is setup as the output variable. This experiment includes a total of 312 samples. Among them, 252 are sample data in the training dataset. The prediction model was used as the training data of the model. Then, 60 samples as the model of the test group data into the best prediction model, after the completion of the test with the actual compressive strength to do the accuracy of the model. The model is tested with a different number of studies (epoch). The default value is set to 5000 increments until the convergence is complete, and the error tolerance is expected to be closer to the actual compressive strength.

4.1. Prediction of ANNs Model Parameters. The mean absolute percentage error (MAPE) of the concrete strength and actual strength predicted by the model under different parameter settings is obtained as shown in Table 2. The minimum MAPE obtained are $10.48 \%$ and $10.46 \%$ for oneinput and two-input network types, respectively. The most accurate prediction made using neuro network is as follows:

(i) For one-input, the network type recommended is 13-1 as one-input-three input layer processing units-one hidden layer processing unit that is trained 2000 times. The minimum MAPE strength of concrete is $10.48 \%$, as the number of hidden layer manufacturing unit increases. Once the number of processing units exceeds a certain number, the training time of the model will increase during the training, and the average absolute error percentage will not be improved.

(ii) For two-input, the network type recommended is 23-1 as two-input-three hidden layer processing units-one output layer processing unit that is trained 2000 times, the best percentage of the average predicted concrete intensity is $10.46 \%$. It can be seen that as the number of hidden layer processing unit increases, the average absolute error percentage obtained by them can reach a smaller error value. If the number of hidden layer processing units exceeds a certain number, it will increase the model in the training process. During training time, the average absolute error percentage will not be improved, so the best predictive model for this type of neural network is the network type 2-3-1. 
TABLe 2: Artificial neural network model training result.

\begin{tabular}{|c|c|c|c|c|c|c|c|c|c|}
\hline \multicolumn{5}{|c|}{ One-input (single entry) } & \multicolumn{5}{|c|}{ Two-input (double entry) } \\
\hline Network type & Hidden layer & Number of training & $R^{2}$ & MAPE (\%) & Network type & Hidden layer & Number of training & $R^{2}$ & MAPE (\%) \\
\hline $1-1-1$ & 1 & 200 & 0.73 & 14.79 & $2-1-1$ & 1 & 200 & 0.73 & 12.85 \\
\hline $1-1-1$ & 1 & 500 & 0.74 & 11.37 & $2-1-1$ & 1 & 500 & 0.74 & 10.63 \\
\hline $1-1-1$ & 1 & 1000 & 0.74 & 14.52 & $2-1-1$ & 1 & 1000 & 0.74 & 12.43 \\
\hline $1-3-1$ & 1 & 2000 & 0.73 & 10.48 & $2-3-1$ & 1 & 2000 & 0.75 & 10.46 \\
\hline $1-5-1$ & 1 & 2000 & 0.75 & 10.98 & $2-2-1$ & 1 & 2000 & 0.74 & 10.58 \\
\hline $1-1-1$ & 1 & 2000 & 0.74 & 10.93 & $2-7-1$ & 1 & 2000 & 0.73 & 10.96 \\
\hline $1-1-1$ & 1 & 3000 & 0.74 & 12.91 & $2-1-1$ & 1 & 3000 & 0.74 & 10.61 \\
\hline $1-1-1$ & 1 & 5000 & 0.74 & 13.49 & $2-1-1$ & 1 & 5000 & 0.73 & 14.79 \\
\hline $1-1-1$ & 1 & 7500 & 0.74 & 13.08 & $2-1-1$ & 1 & 7500 & 0.74 & 12.84 \\
\hline $1-1-1$ & 1 & 15000 & 0.74 & 14.31 & $2-1-1$ & 1 & 15000 & 0.75 & 13.23 \\
\hline $1-1-1$ & 1 & 20000 & 0.74 & 11.45 & $2-1-1$ & 1 & 20000 & 0.74 & 11.01 \\
\hline
\end{tabular}

Table 3 gives the result when inserting the remaining 60 sets of data as the test group data of the model into the best predicted model of this research. The MAPE is $10.94 \%$ for one-input and $10.87 \%$ for two-input. The absolute error rate can be reduced by increasing the model input, for example, the average ultrasonic velocity and the standard deviation.

\subsection{Prediction of Adaptive Neural Fuzzy Inference System} (ANFIS). The MATLAB environment and command window for ANFIS model development and process are setup with four different numbers of attribution functions to each input (this research uses 2, 3, 4, and 5) and eight kinds of attribution function types: trimf, trapmf, gbellmf, gaussmf, gauss2mf, pimf, dsigmf, and psigmf. A total of 32 ANFIS prediction models are established. In order to observe whether there is a better predictive result, this study attempts three things. First is to increase the input of the model: the average ultrasonic wave velocity and the standard deviation as inputs of the ANFIS predictive concrete strength model. Second is to compare the different attributive function types. Third is to compare the MAPE of the actual concrete strength and the strength predicted by the model. Table 4 shows the MAPE when examining the accuracy in prediction. The average value of the ultrasonic wave is used as the input variable of ANFIS. Result shows that one-input with 5 attribution functions gives smallest MAPE of $9.37 \%$ and $9.18 \%$ for two-input model.

Similar to ANN model validation, the same 60 test data are used to validate the best ANFIS training model for validation purpose. The obtained MAPE from these 60 test data is shown in Table 5.

4.3. Result Analysis. The outputs that predict the estimated concrete compressive strength are compared directly with the actual compressive strength obtained. The mean absolute percentage error MAPE of the linear and nonlinear regression are $11.17 \%$ and $17.66 \%$, respectively, and the accuracy is not enough. The best predictive model is based on the adaptive neurocognitive fuzzy inference system, and the average absolute error percentage MAPE is $9.86 \%$. The research results can provide valuable information when UPV tests are used to estimate concrete compressive strength. It is also proved that the accuracy of the prediction is higher when using the artificial intelligence algorithm. The artificial intelligence method used to establish the prediction model does improve the prediction accuracy of concrete compressive strength, as shown in Table 6.

Table 7 is the result of the prediction model established by different methods in this study. The artificial intelligence method does improve the prediction accuracy of concrete compressive strength prediction model. This study attempted to increase the input variable of the model, for example, the average velocity of the ultrasonic pulse velocity and standard deviation. As shown in Table 7, by increasing the number of input variables, from one to two, the prediction results from both ANN and ANFIS models are slightly improved. In order to understand the type of model and parameter settings and the concrete strength prediction accuracy, it is necessary to compare the result using the linear regression and nonlinear regression. The mean absolute percentage error MAPE obtained by linear regression and nonlinear regression are $11.17 \%$ and $17.66 \%$, respectively. And, the ANN is $10.940 \%$ for one-input and $10.87 \%$ for two-input. The best predictive model is based on the adaptive neurocognitive inference system with the average absolute error percentage MAPE of $9.86 \%$.

The results in Table 7 show that the model does improve the prediction accuracy of concrete compressive strength. When attempting to increase the input of the model, the results show that the minimum error rate of the concrete is less than $10.87 \%$ and $9.79 \%$, respectively, for ANN and ANFIS. The results are better than the predictions of the single input, which proves that the increase in the input of the model can reduce the absolute error percentage.

\section{Conclusions}

To improve the result of nondestructive tests, the average velocity of ultrasonic waves obtained from each specimen was calculated. Adaptive neurocognitive inference system (ANFIS) and the neural network (ANN) method are used to predict the compressive strength of concrete. Within 312 test samples, 252 test samples are randomly chosen to be the train data in this study. The remaining 60 test samples are set as the test data to evaluate the prediction model accuracy. 
TABLE 3: Results of the test group data into the ANN.

\begin{tabular}{lccccc}
\hline Network type & Hidden layer & \multirow{2}{*}{$\mathrm{R}^{2}$} & Standard deviation & Input type & \multicolumn{2}{c}{ MAPE (\%) } \\
& & & & Training & Testing \\
\hline $1-3-1$ & 1 & 0.74 & 16.42 & Single entry & 10.48 \\
$2-3-2$ & 1 & 0.75 & 16.34 & Double entry & 10.94 \\
\hline
\end{tabular}

TABLE 4: Adaptive neuro-fuzzy inference system (ANFIS) model.

\begin{tabular}{|c|c|c|c|c|c|c|c|c|}
\hline \multirow{3}{*}{ Attribution function } & \multicolumn{4}{|c|}{ MAPE (\%) } & \multicolumn{4}{|c|}{ MAPE (\%) } \\
\hline & \multicolumn{4}{|c|}{ One-input: number of functions } & \multicolumn{4}{|c|}{ Two-input: number of functions } \\
\hline & {$[2]$} & [3] & [4] & {$[5]$} & {$\left[\begin{array}{ll}2 & 2\end{array}\right]$} & {$\left[\begin{array}{ll}3 & 3\end{array}\right]$} & {$\left[\begin{array}{ll}4 & 4\end{array}\right]$} & {$\left[\begin{array}{ll}5 & 5\end{array}\right]$} \\
\hline Trimf & 10.04 & 9.80 & 9.66 & 9.80 & 9.98 & 9.94 & 10.05 & 10.46 \\
\hline Trapmf & 10.26 & 10.94 & 9.48 & 10.00 & 10.52 & 10.94 & 10.43 & 9.18 \\
\hline Gbellmf & 9.73 & 9.89 & 9.46 & 9.37 & 9.68 & 9.89 & 10.40 & 9.56 \\
\hline Gaussmf & 9.76 & 10.01 & 9.41 & 9.76 & 9.77 & 10.85 & 10.28 & 9.94 \\
\hline Gauss2mf & 9.78 & 10.01 & 9.49 & 9.88 & 10.18 & 10.54 & 10.26 & 10.98 \\
\hline Pimf & 10.48 & 10.50 & 10.50 & 10.50 & 10.73 & 10.66 & 10.31 & 10.49 \\
\hline Dsigmf & 10.15 & 9.97 & 9.46 & 9.69 & 10.11 & 10.56 & 10.67 & 10.58 \\
\hline Psigmf & 10.15 & 9.91 & 9.46 & 9.43 & 10.11 & 10.57 & 10.67 & 10.56 \\
\hline Trimf & 10.04 & 9.80 & 9.66 & 9.80 & 9.98 & 9.94 & 10.05 & 10.46 \\
\hline Trapmf & 10.26 & 10.94 & 9.48 & 10.00 & 10.52 & 10.94 & 10.43 & 9.18 \\
\hline
\end{tabular}

TABLE 5: Results of the test group data into the ANFIS.

\begin{tabular}{lcccc}
\hline Attribution function & Number of function & Standard deviation & Input type & \multicolumn{2}{c}{ MAPE (\%) } & Training \\
& & & Testing \\
\hline Gbellmf & 5 & 13.90 & Single entry & 9.37 \\
Trapmf & 5 & 13.95 & Double entry & 9.18 \\
\hline
\end{tabular}

TABLE 6: Comparison of ANFIS, ANN, linear, and nonlinear regression model prediction accuracy.

\begin{tabular}{lccc}
\hline Forecasting model & Prediction formula and parameter setting & Standard deviation & Single entry $($ MAPE \%) \\
\hline Linear regression & $f c=0.3713 V-1162.8$ & 16.80 & 11.17 \\
Nonlinear regression & $f c=0.8648 \exp (0.0015 \mathrm{~V})$ & 23.13 & 17.66 \\
ANN test & Network type $(1-3-1)$ & 16.42 & 10.94 \\
AI $<\quad$ ANFIS test & The number of functions: 5 & 13.90 & $\mathbf{9 . 8 6}$ \\
\end{tabular}

${ }^{*} f c$ is the compressive strength and $V$ is the average wave speed.

TABLE 7: ANN and ANFIS model prediction accuracy.

\begin{tabular}{lccc}
\hline Forecasting model & Parameter setting & Standard deviation & \multicolumn{2}{c}{ MAPE (\%) } & One-input & Two-input \\
\hline ANN model & Hidden layer & 16.34 & 10.94 \\
ANFIS model & The number of functions: [5 5] & 10.87 & 9.86 \\
\hline
\end{tabular}

The results show that traditional concrete compressive strength estimations have an average of over $20 \%$ mean absolute percentage error when compared with the actual compressive strength obtained by destructive tests. The MAPE in predicting the compressive strength for linear and nonlinear regression models are $11.17 \%$ and $17.66 \%$, respectively. Based on the result obtained, the combined two different artificial intelligence methods in establishing a predictive strength model becomes more reliable, and the prediction is more accurate. When compared with the predictions from the other two models with one-input (average ultrasonic pulse wave velocity), the best MAPE values of $10.94 \%$ and $9.86 \%$ were obtained by the ANN test and ANFIS test, respectively. In addition, the prediction results from two-input (average ultrasonic pulse wave velocity and standard deviation) show that the minimum error rates of the concrete are $10.87 \%$ and $9.79 \%$, which imply that the results are better than the predictions of the one input. 
For the collected sample, the research results have shown that the increase in the input of the model can reduce the mean absolute percentage error.

\section{Data Availability}

The research data are collected in collaboration with a local material testing laboratory in Taiwan. The testing sample belongs to the local lab's customer. The authors have signed a nondisclosure agreement to keep the raw data information confidential. The authors can only mention certain amount of raw data according to the requirement of not publishing the completed set of raw data but only the analytical data.

\section{Conflicts of Interest}

The authors declare that they have no conflicts of interest.

\section{References}

[1] Y. R. Wang, W. T. Kuo, S. S. Lu et al., "Applying support vector machines in rebound hammer test," Advanced Materials Research, vol. 853, pp. 600-604, 2014.

[2] B. S. Mohammed, N. J. Azmi, and M. Abdullahi, "Evaluation of rubbercrete based on ultrasonic pulse velocity and rebound hammer tests," Construction and Building Materials, vol. 25, no. 3, pp. 1388-1397, 2011.

[3] R. Pucinotti, "Reinforced concrete structure: non destructive in situ strength assessment of concrete," Construction and Building Materials, vol. 75, pp. 331-341, 2015.

[4] J.-S. Chou and A.-D. Pham, "Enhanced artificial intelligence for ensemble approach to predicting high performance concrete compressive strength," Construction and Building Materials, vol. 49, pp. 554-563, 2013.

[5] B. Vakhshouri and S. Nejadi, "Prediction of compressive strength of self-compacting concrete by ANFIS models," Neurocomputing, vol. 280, pp. 13-22, 2018.

[6] F. Khademi, S. M. Jamal, N. Deshpande, and S. Londhe, "Predicting strength of recycled aggregate concrete using artificial neural network, adaptive neuro-fuzzy inference system and multiple linear regression," International Journal of Sustainable Built Environment, vol. 5, no. 2, pp. 355-369, 2016.

[7] K. Behfarnia and F. Khademi, "A comprehensive study on the concrete compressive strength estimation using artificial neural network and adaptive neuro-fuzzy inference system," Iran University of Science and Technology, vol. 7, no. 1, pp. 71-80, 2017.

[8] S. T. Bhat and C. W. Lovell, Use of Coal Combustion Residues and Foundry Sands in Flowable Fill, Publication FHWA/IN/ JHRP-96/02: Joint Highway Research Project, Indiana Department of Transportation and Purdue University, West Lafayette, IN, USA, 1996.

[9] ACI-229R, Controlled-Low Strength Materials, American Concrete Institute, Farmington Hills, MI, USA, 2005.

[10] K. Komlos, S. Popovics, T. Nürnbergerova, B. Babal, and J. S. Popovics, "Ultrasonic pulse velocity test of concrete properties as specified in various standards," Cement and Concrete Composites, vol. 18, no. 5, pp. 357-364, 1996.

[11] F. Khademi and S. M. Jamal, "Predicting the 28 days compressive strength of concrete using artificial neural network," i-manager's Journal on Civil Engineering, vol. 6, no. 2, 2016.
[12] M. Nikoo, P. Zarfam, and M. Nikoo, "Determining displacement in concrete reinforcement building with using evolutionary artificial neural networks," World Applied Sciences Journal, vol. 16, no. 12, pp. 1699-1708, 2012.

[13] D. Padmini, K. Ilamparuthi, and K. P. Sudheer, "Ultimate bearing capacity prediction of shallow foundations on cohesionless soils using neuro fuzzy models," Computers and Geotechnics, vol. 35, no. 1, pp. 33-46, 2008.

[14] S. Kahraman, "Evaluation of simple methods for assessing the uniaxial compressive strength of rock," International Journal of Rock Mechanics and Mining Science, vol. 38, no. 7, pp. 981-994, 2001.

[15] H. Y. Qasrawi, "Concrete strength by combined nondestructive methods simply and reliably predicted," Cement and Concrete Research, vol. 30, no. 5, pp. 739-746, 2000.

[16] M. Nehdi, H. E. Chabib, and A. Naggar, "Predicting performance of self-compacting concrete mixtures using artificial neural networks," ACI Materials Journal, vol. 98, no. 5, pp. 394-401, 2001.

[17] G. Trtnink, B. Kavcic, and G. Turk, "Predicting of concrete strength using ultrasonic pulse velocity and artificial neural networks," Ultrasonics, vol. 49, no. 1, pp. 53-60, 2009.

[18] I.T. Yusuf, Y. A. Jimoh, and W. A. Salami, “An appropriate relationship between flexural strength and compressive strength of palm kernel shell concrete," Alexandria Engineering Journal, vol. 55, no. 2, pp. 1553-1562, 2016.

[19] T. R. Naik, V. M. Malhotra, and J. S. Popovics, The Ultrasonic Pulse Velocity Method: Handbook on Non-Destructive Testing of Concrete, CRC Press, Boca Raton, FL, USA, 2004.

[20] American Concrete Institute (ACI 228), Non-Destructive Test Methods for Evaluation of Concrete in Structures, ACI 228.2R98, Farmington Mills, MI, USA, 1998.

[21] S.C. Kou, C.S. Poon, and H.W. Wan, "Properties of concrete prepared with low-grade recycled aggregates," Construction and Building Materials, vol. 36, pp. 881-889, 2012.

[22] R. Latif, Al. Mufti, and A.N. Fried, "The early age nondestructive testing of concrete made with recycled concrete aggregate," Construction and Building Materials, vol. 37, pp. 379-386, 2012.

[23] G. Barluenga, J. Puentes, and I. Palomar, "Early age monitoring of self-compacting concrete with mineral additions," Construction and Building Materials, vol. 77, pp. 66-73, 2015.

[24] M. Molero, I. Segura, M. A. G. Izquierdo, J. V. Fuente, and J. J. Anaya, "Sand/cement ratio evaluation on mortar using neural networks and ultrasonic transmission inspection," Ultrasonics, vol. 49, no. 2, pp. 231-237, 2009.

[25] S. O. Naffa, M. Goueygou, B. Piwakowski, and F. Buyle-Bodin, "Detection of chemical damage in concrete using ultrasound," Ultrasonics, vol. 40, no. 1-8, pp. 247-251, 2002.

[26] M. Ohtsu, M. Shigeishi, and Y. Sakata, "Non-destructive evaluation of defects in concrete by quantitative acoustic emission and ultrasonics," Ultrasonics, vol. 36, no. 1-5, pp. 187-195, 1998.

[27] J. A. Bogas, M. G. Gomes, and A. Gomes, "Compressive strength evaluation of structural lightweight concrete by nondestructive ultrasonic pulse velocity method," Ultrasonics, vol. 53, no. 5, pp. 962-972, 2013.

[28] R. J. Sztukiewicz, "Application of ultrasonic methods in asphalt concrete testing," Ultrasonics, vol. 29, no. 1, pp. 5-12, 1991.

[29] M. Colombo and R. Felicetti, "New NDT techniques for the assessment of fire-damaged concrete structures," Fire Safety Journal, vol. 42, no. 6-7, pp. 461-472, 2007. 
[30] BSI, Method for Determination of Compressive Strength of Concrete Cubes, BS 1881, Part116, British Standards Institution, London, UK, 1983.

[31] T. Catalina, V. Iordache, and B. Caracaleanu, "Multiple regression model for fast prediction of the heating energy demand," Energy and Buildings, vol. 57, pp. 302-312, 2013.

[32] S. S. K. Kwok and E. W. M. Lee, "A study of the importance of occupancy to building cooling load in prediction by intelligent approach," Energy Conversion and Management, vol. 52, no. 7, pp. 2555-2564, 2011.

[33] B. Dong, C. Cao, and S. E. Lee, "Applying support vector machines to predict building energy consumption in tropical region," Energy and Buildings, vol. 37, no. 5, pp. 545-553, 2005.

[34] Y. Wu, H. Wang, B. Zhang et al., "Using radial basis function networks for function approximation and classification," ISRN Applied Mathematics, vol. 2012, Article ID 324194, 34 pages, 2012.

[35] J. L. Rogers, "Simulating structural analysis with neural network," Journal of Computing in Civil Engineering, vol. 8, no. 2, pp. 252-265, 1994.

[36] J. Ghaboussi and A. Joghataite, "Active control of structures using neural networks," Journal of Engineering Mechanics, vol. 121 , no. 4 , pp. 555-567, 1995.

[37] J. Sobhani, M. Najimi, A. R. Pourkhorshidi, and T. Parhizkar, "Prediction of the compressive strength of no-slump concrete: a comparative study of regression, neural network and ANFIS models," Construction and Building Materials, vol. 24, no. 5, pp. 709-718, 2010.

[38] Z. Yuan, L. N. Wang, and X. Ji, "Prediction of concrete compressive strength: research on hybrid models genetic based algorithms and ANFIS," Advances in Engineering Software, vol. 67, pp. 156-163, 2014.

[39] Q. Zhou, "Estimation of compressive strength of hollow concrete masonry prisms using artificial neural networks and adaptive neuro-fuzzy inference systems," Construction and Building Materials, vol. 125, pp. 417-426, 2016.

[40] P. J. L. Adeodato, A. L. Arnaud, G. C. Vasconcelos, R. C. L. V. Cunha, and D. S. M. P. Monteiro, "Ensembles improve long term prediction accuracy over single networks," International Journal of Forecasting, vol. 27, no. 3, pp. 661$671,2001$.

[41] F. Khademi and K. Behfarnia, "Evaluation of concrete compressive strength using artificial neural network and multiple linear regression models," Iran University of Science \& Technology, vol. 6, no. 3, pp. 423-432, 2016.

[42] W. Shixiang, "ANFIS applied to concrete compression strength prediction mode," Master's thesis, National Kaohsiung University of Applied Science and Technology of Civil Engineering and Disaster Prevention Technology, Kaohsiung, 2012.

[43] J. H. Bungey, J. H. Millard, and M. G. Grantham, Testing of Concrete In Structures, Taylor \& Francis, New York, NY, USA, 2006.

[44] B. Ahmadi-Nedushan, "Prediction of elastic modulus of normal and high strength concrete using ANFIS and optimal nonlinear regression models," Construction and Building Materials, vol. 36, pp. 665-673, 2012.

[45] M. G. Hernández, M. A. G. Izquierdo, A. Ibáñez, J. J. Anaya, and L. G. Ullate, "Porosity estimation of concrete by ultrasonic NDE,” Ultrasonics, vol. 38, no. 1-8, pp. 531-533, 2000.

[46] SILVER SCHMIDT, Electronic Concrete Test Hammer: Enkay Enterprises Information, http://www.enkaymachine.org/ proceq6.htm.
[47] L. Y. Yu and S. Yong, "The relationship between the compressive strength of concrete slabs and rebound hammer research," Taiwan National Kaohsiung University of Applied Science and Technology, vol. 37, no. 2, 2008.

[48] J. S. Chou and D. K. Bui, "Modeling heating and cooling loads by artificial intelligence for energy-efficient building design," Energy and Buildings, vol. 82, pp. 437-446, 2014.

[49] T. M. S. Elhag and A. H. Boussabaine, "Tender price estimation using artificial neural networks. II: modelling," Journal of Financial Management of Property and Construction, vol. 7, no. 1, pp. 49-64, 2002.

[50] T. M. S. Elhag, "Cost modeling: neural networks vs. regression techniques," in Proceedings of International Conference on Construction Information Technology (INCITE), Construction Industry Development Board Malaysia (CIDB), Langkawi, Malaysia, May 2004.

[51] M. B. Jaksa and H. R. Maier, "Future challenges for artificial neural network modeling in geotechnical engineering," in Proceedings of 12th International Conference of International Association for Computer Methods and Advances in Geomechanics (IACMAG), Goa, India, October 2008.

[52] A. A. Shah, S. H. Alsayed, H. Y. Abbas, and A. Al-Salloum, "Predicting residual strength of non-linear ultrasonically evaluated damaged concrete using artificial neural network," Construction and Building Materials, vol. 29, pp. 42-50, 2012.

[53] J. S. R. Jang, C. T. Sun, and E. Mizutani, Neuro-Fuzzy and Soft Computing, Prentice-Hall International Inc., Upper Saddle River, NJ, USA, 2015. 


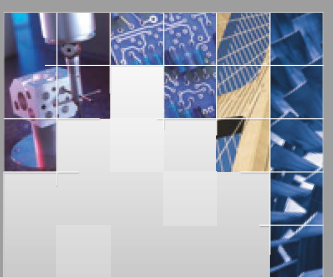

\section{Enfincering}
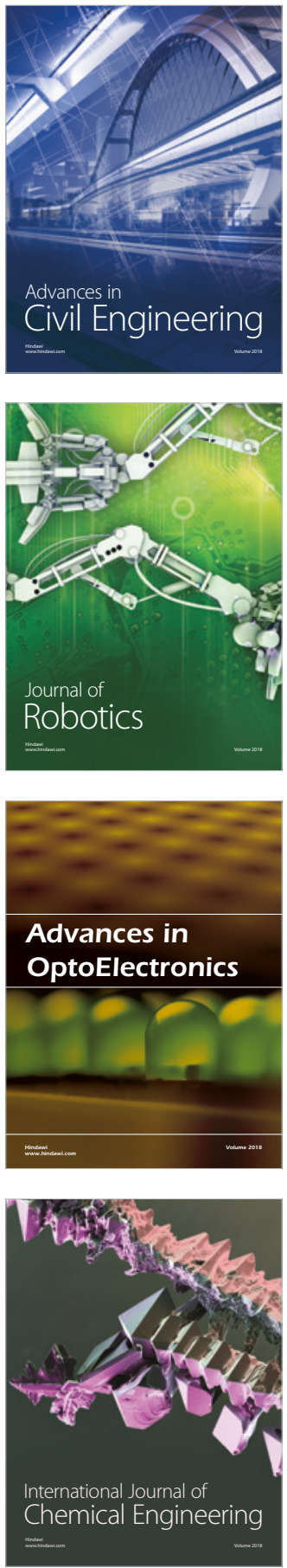

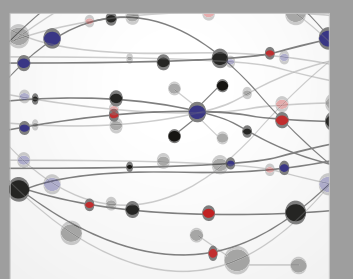

\section{Rotating \\ Machinery}

The Scientific World Journal

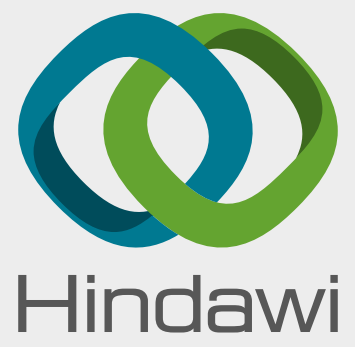

Submit your manuscripts at

www.hindawi.com
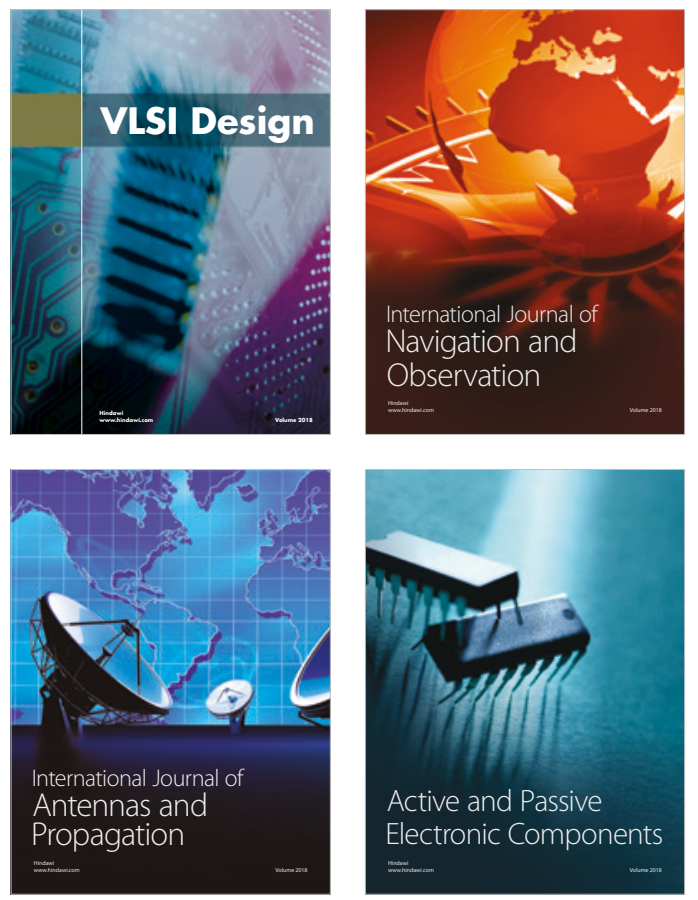
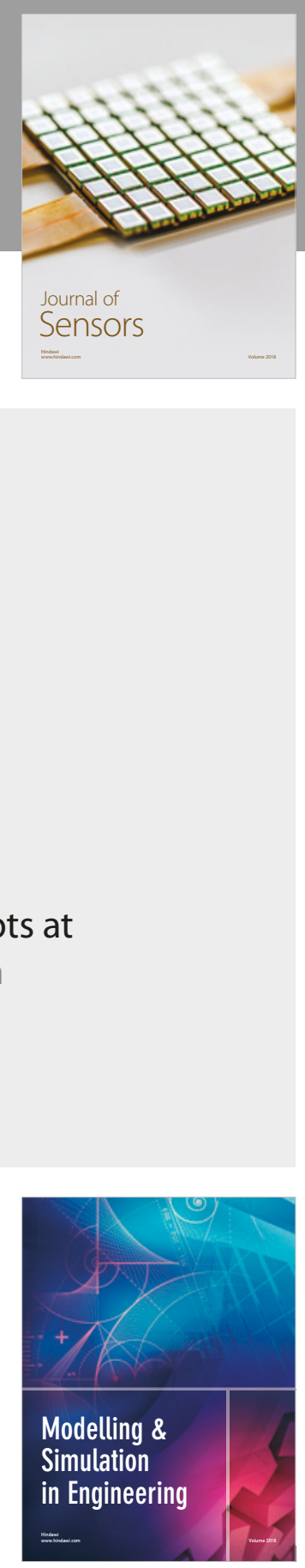

\section{Advances \\ Multimedia}
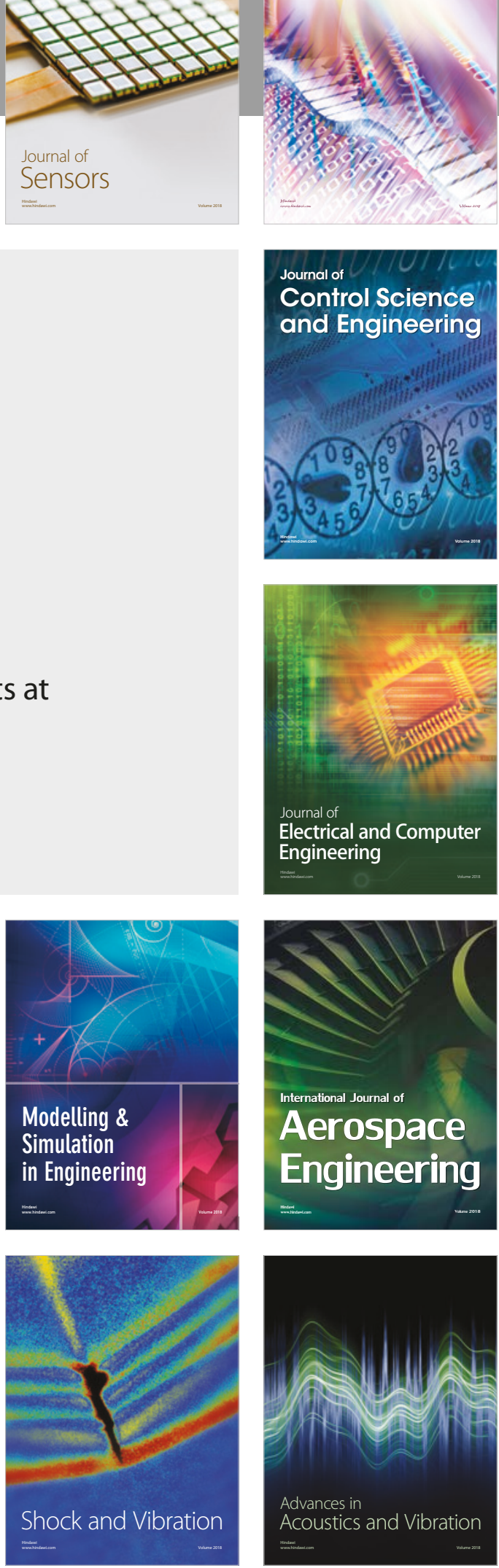